\title{
Self-Regulation in Text Processing
}

\author{
Frank P. C. M. de Jong \\ Robert-Jan Simons \\ Tilburg University, The Netherlands
}

In this paper an experiment is reported on the influence of two variations of instructions on learning performance and thinking-aloud protocols of 64 pupils from secondary schools. Furthermore, differences between successful and less successful pupils in self-regulatory processes during text processing are described. The texts consisted of instructions on how to use a computer keyboard and a text-editor. Learning performance referred to both knowledge and application. The variation in instructions did not influence the learning performance and the thinking-aloud protocols (either quantitatively or qualitatively), but the variable Marks/No Marks did. The main differences between successful and less successful pupils occurred in orientation processes, especially with regard to Reflection on Foreknowledge and Gaps in Foreknowledge. Differences also turned up for processes such as Process Selection and Making Summaries. The results are discussed in light of the results from a prior study with an informative text.

\section{Introduction}

When learning from texts in instructional contexts pupils are often directed by instructional aids built into the text (like learning goals, summaries, pictures, schemata and so on) or by recommendations given by a teacher (a lecture often precedes text learning; teachers prescribe certain parts of texts; instructional goals are formulated or suggested). Even though there is thus often much help from the outside, pupils still have to do the actual learning themselves. In case of the most optimal help by the material or by a teacher, the pupil still has to monitor his/her comprehension, to decide when he/she is ready to be tested, to select an adequate processing strategy and so on. When there is less help from the instructional material or a teacher, the student has to «self-regulate» even more.

In previous publications from our laboratory we described our model of self-regulation of text learning (De Jong, 1987a; Simons \& Lodewijks, 1987; Simons \& Vermunt, 1986). The self-regulation model of text learning (see figure 1) consists of three parts: before, during and after executing the learning task. Before learning a person can prepare the learning activities by analysing the task demands and learning goals (reproduction, recognizing, problem solving, transfer), modality of the task (visual, verbal, linguistic, the conceptual degree of 
difficulty, physical or psychological structure) and the individual characteristics as a learner (the available techniques and strategies, foreknowledge, attitudes, interest, motivation). The information gathered by orientation activities can be used in the decision what one is going to do or by planning the learning route. In spite of the fact that task analytics and educational psychologists agree on the usefulness of the orientation and planning processes, most students (even the successful ones) jump over one or both stages and regulate their learning during execution. Of course one can not foresee everything beforehand. However, the attitude of problem-orientated learning, $i$. e . coming in action when an obstacle is encountered, puts a heavy load on the executive control processes. An active observing (monitoring) of what the effects are of the employed learning activities, a constant checking whether one is going to reach the learning goals is of great importance. One can check comprehension or memorising by testing techniques such as summarizing, recalling, paraphrasing, comparing conclusions with the text, answering self-posed questions, and so on. The outcomes of the executive processes, such as monitoring, testing and reflection (thinking about the stream of ongoing cognitive actions) have their impact on the directing of the execution. Thus a re-orientation, redirection (change of planning or activities) or persistence may be the consequence. It could also result in knowledge and understanding of the students' own learning processes, which can be used to regulate text processing in future situations. The same could be the result of the evaluation after the execution where the degree is judged in which the learning goals have been reached.

Figure 1. Modèle d'auto-régulation de l'apprentissage durant le traitement d'un texte

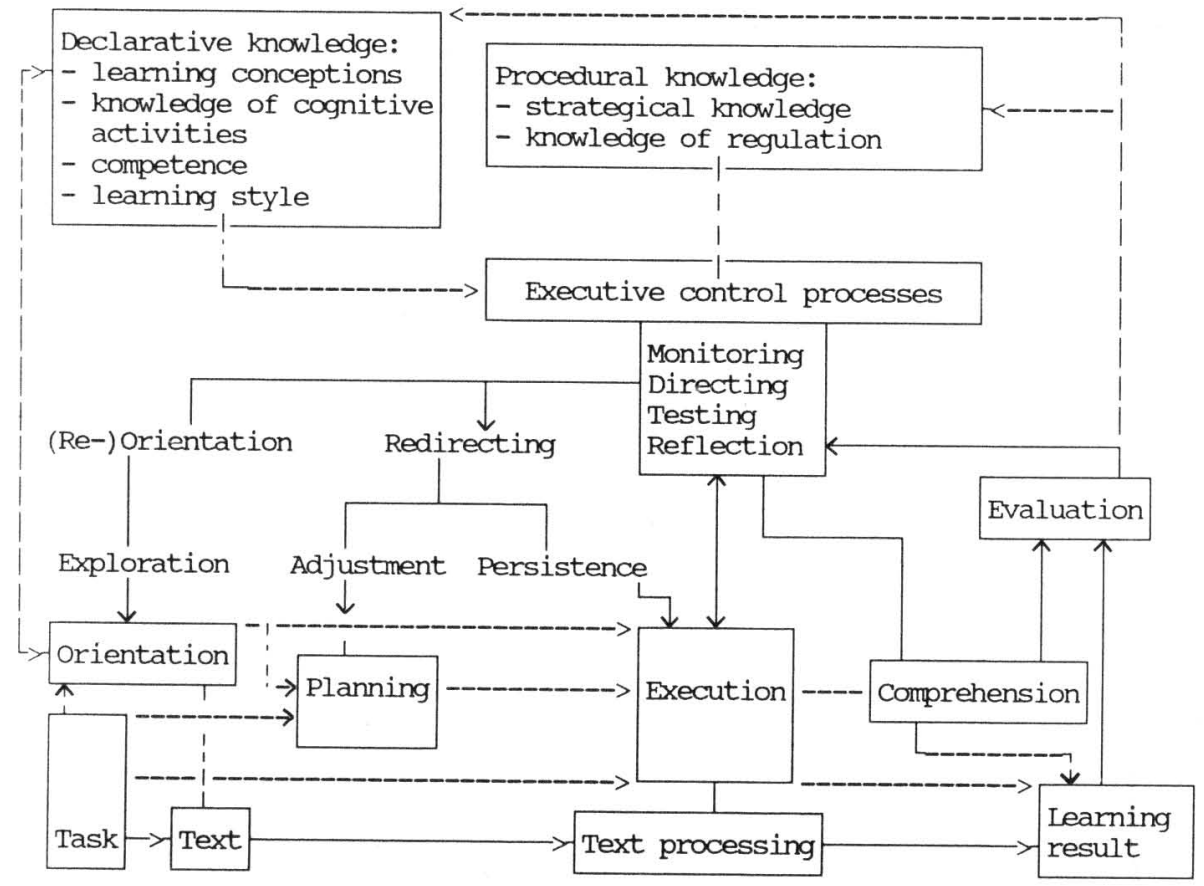

Figure 1. Model of self-regulated learning during text processing

In a first study (Simons \& Lodewijks, 1987), we found differences between successful and less successful text learners in the regulation of text learning. Successful students tested in a way that was tuned to the learning goal, while less successful students tested on memory. Furthermore, a short training succeeded in changing this testing behaviour of less successful 
students as well as their learning performance. Finally, there were interesting differences between different tasks. The number of subjects, however, was rather small.

Therefore we started a study with a greater number of students, aiming at deepening and replicating these results in a larger sample and to study the qualities of the thinking aloud method in studying self-regulation. Two kinds of texts were used: informative texts on biology subjects like burns and hair and instructive texts on the use of a keyboard and a text-editor. The results of the study on the informative texts were presented elsewhere (De Jong, 1987a). This paper presents the results on the instructive texts, prescribing how to act in a certain situation. In both studies (employing the same subjects) there were three main research questions: 1) What is the effect of the demand to verbalize at marks versus continuous verbalization (see Olshavsky, 1976)?, 2) What are the effects of instructions and examples to verbalize certain kinds of thoughts?, and 3) What are the differences between successful and less successful students in the regulation of text learning? Furthermore, we were interested in differences between the regulation of the two kinds of texts. The study using informative texts showed that there were hardly any differences as to the contrast Marks-No Marks and general and specific verbalizing instructions. There were, however, significant differences between successful and less successful students in learning activities, especially in reference to the categories Monitoring, Directing and Testing. Process scores predicted learning results better than any other variable measured. Could we find the same results when using texts aiming at teaching how to use a keyboard or an editor?

\section{Method}

\section{Subjects}

Thirty-two girls and thirty-two boys were selected as «successful» or «less successful» pupils according to introduction criteria of their schools and their performance in a national examination. The subjects were first year secondary school pupils about twelve years old.

\section{Stimuli}

Two texts were used. One text, called Key-Board, dealt with an explanation of the computer memory, the key-board and how to use the key-pad when editing a text. The other text, called Editor, dealt with an explanation of the computer memory, the retrieval and editing of files and how to use the function keys to edit a text.

Presentations of the texts, on an Olivetti PC M19 screen, were freely chosen by the students from a menu. Each text was presented in paragraphs, each paragraph having a headline. The first reading of these paragraphs was serial, but at any time the presentation of a text fragment could be stopped or started by the subject. Every paragraph that had already been read could be chosen for rereading. The table of contents with which every learning session started and which consisted of the nineteen (Editor) or twenty (Key-Board) headlines remained on the screen with the menu during the presentation of a paragraph (De Jong, 1987a).

When the level Mark of the variable Moment of Verbalization was in operation a green screen was presented every time the RETURN-key was pushed in order to stop the presentation of a paragraph. When a pupil had nothing more to tell, he or she again pushed the RETURN-key to return to the menu.

The succession of paragraph presentation was registered on-line. By graphic presentation of the reading succession the same three pupil groups with different reading behaviour could be identified, in agreement with De Jong (1987a).

By means of the following question information was gathered about the pupils' learning concept: "What does learning mean to you?». When they could not answer this question it was paraphrased into: «Why are you going to this type of school?». The answers 
could be analyzed into four categories according to trends in the answers. The categories can be described as «Knowing in order to know», «I have got to», «Profession perspective» and «Individual interest» (De Jong, 1987a).

For operationalization of our interest in the subjects' subjective competence the next two questions were asked: «I learn for a test paper, until I think I will score a... for it» (competence 1) and «I am satisfied with a... for a test paper» (competence 2). Pupils had to fill in a number between zero (0) and ten (10), in which 0 is very insufficient.

In order to operationalize the factor metamemory, the awareness of the stored information and retrievability of it (Flavell \& Wellmann, 1977), the pupils were asked the following question before starting the test: «How many of the five questions and ten practice exercises will you answer correctly?». Metacognition, as awareness of their actual test performance or result of their learning process, was operationalized by asking the following question after the test had been done: «How many of the questions and the practice exercises do you think you answered correctly?» The same questions were asked two weeks later when the pupils had to do the same test differing only in that the questions of the test were in a different order.

\section{Procedure}

In two introductory sessions the participants were not only trained in «learning aloud», but also in using the menu-guided presentation of the texts.

During the introductory session half of the pupils were instructed to freely think aloud during learning, and the other half were instructed only to verbalize those thoughts that were related to self-regulating activities. A list of 44 examples of thought expressions that were related to self-regulation was given to both groups. The list that was given to the first group was extended with 17 thought expressions that were not related to self-regulation activities.

The two learning sessions on the Key-Board and the Editor took place on two different days in the fourth week following the introductory sessions. In the first week the subjects learned a vocabulary task. In the second week they learned an informative text and in the third week they learned a text about theory of chances. In this paper only the results of the instructive texts on Key-Board and Editor will be presented and discussed.

The session time was limited to a maximum of 30 minutes. The pupils were free to stop whenever they wanted. Before each learning session the subjects were told that, afterwards, they would be subjected to a test consisting of 5 four-choice questions about the text and 10 practice exercises dealing with editing a text. Two weeks after the learning sessions subjects had to do a test consisting of the same questions and practice exercises, but in a different order. Furthermore, they were reminded of the things they had to verbalize and whether they had to learn aloud constantly or only when they encountered a green empty screen.

During the learning sessions the experimenter restricted his remarks (such as: «Could you tell me what you are thinking?») to the moments the green screen was presented. In the No-Mark condition the experimenter only stimulated to think aloud at those moments he thought it was necessary on the basis of a subject's overt behaviour (long pauses or wrinkling the forehead or brows). No feedback was given during the learning task. During the test feedback was given about the practice exercises. This feedback consisted of the remark: 'WRONG, try again'. And in case the second action was wrong too: 'WRONG, the computer will execute it.'

The thinking-aloud protocols were recorded on tape, typed out literally and analyzed into units consisting of one process. Units were not restricted to the limits of a sentence. Parallel with the identification of process units they were analyzed into five general categories: Transforming, Orientation, Monitoring, Directing and Testing. Each category consists of several operations (De Jong, 1987b). A sixth category, Off-Task Remarks, deals with 
the experimenter's stimulations and other remarks made by him or by the subject. The process analyzing scheme is a modification of the scheme that was developed by Vermunt, Lodewijks and Simons (1986). Modifications are based on analyzed protocols of a pilot study, a study on vocabulary, text and problem solving learning.

The category Transformation concerns verbalizations that indicate mediation activities. By these activities the information on paper is transformed into information in the student's mind. One can think of activities like: reading, drilling, copying, calculating and adding information, drawing on previous school learning or one's own experience (e. g. "This key is on the other side of the key-board of my own computer»).

The category Orientation includes activities that are aimed at gathering information about the learning task only (orientation before learning) or the problem situation during learning in order to select, allocate or change (ongoing) learning activities. Examples of orientation activities are: glancing through the task, mentioning one's normal study strategy, reflecting on positive or negative student characteristics and reflecting on (gaps in) the foreknowledge.

Monitoring activities function as the finger on the pulse. Verbalizations are the reflection of keeping an eye on the proceeding of one's own learning process. They are a kind of «learning watchers». Examples of monitoring activities are: noting positive or negative interresults, task characteristics, uncomprehended words, sentences or text fragments and remainder of study time and making an interevaluation.

Activities that belong to the category Directing express management of the learning behaviour by the student himself. One can think of process selection and allocation (planning), problem identification, selecting information as an object of attention, dividing a problem into subproblems, asking oneself questions, ignoring an uncomprehended word or expect that classification will follow. Even rereading, if not preceded by a statement like «I'm going to reread that» (process selection), expresses a directing of one's learning activities.

Testing is the category with activities used to check whether one has acquired information or comprehension or to check whether learning goals have been reached. Activities like paraphrasing, summarizing, -drawing conclusions, solving exercises, recalling and comparison of text fragments are covered by the category testing.

\section{Design}

The variable Instruction (directed/non-directed) was a factor between subjects and assigned to a subject during the whole experiment. The variable Student Level (successful/unsuccessful) was counterbalanced over the variable Instruction, as was the variable Sex. Because the variable Moment of Verbalization (thinking aloud at marked points or constantly) was a within variable, two texts of the same level of difficulty were necessary. Both texts were counterbalanced over the variable Moment of Verbalization. The order of presentation of both the two texts and the two levels of the variable Moment of Verbalization was counterbalanced over the subjects.

\section{Results}

Data were subjected to MANOVA analyses and regression analyses. The regression analyses only concern the data gathered under the condition No Marks in which subjects constantly verbalized. In case variates were added to factors of MANOVAs and were univariately tested, Bonferroni adjustments were applied. So stars indicate significancy at adjusted $\alpha$-levels $(* \leqslant 0.05 ; * * \leqslant 0.01 ; * * * \leqslant 0.001)$.

First step in the analyses was to determine an effect of the experimental variables on the two dependent variables Learning Performances. Therefore, a MANOVA was conducted with the factors Instruction and Student Level as between factors and the factors Moment of Verbalization and Time as within factors. Only the factors Student Level $(F(1,60)=13.98$; 
$P \leqslant 0.001)$ and Time $(F(1,60)=-20.83 ; P \leqslant 0.001)$ had significant main effects. The mean performances for successful pupils was $8.9(S D=5.1)$ and $6.0(S D=6.5)$ for unsuccessful pupils. No interactions were found.

A second MANOVA aimed at determining the effect of the experimental variables on the number of verbalized processes as dependent variables. This MANOVA had the between factors Instruction and Student Level and the factor Moment of Verbalization as the within factor. A significant main effect was assessed for the factors Student Level $(F(1,58)=7.54 ; P \leqslant 0.01)$ and Moment of Verbalization $(F(1,58)=7.44 ; P \leqslant 0.01)$. The mean amount of verbalized processes for successful pupils was $123.4(S D=56.2)$ and 94.1 $(S D=45.5)$ for unsuccessful pupils. The mean amount of verbalized processes under the condition No Marks was $99.2(S D=53.3)$ and $118.3(S D=51.3)$ under the condition Marks. In a third MANOVA with the same factors and the different categories as variates it was determined that the effect of the factor Student Level concerned the category Orientation $\left(F(1,58)=17.66 ; P \leqslant 0.001^{* * *}\right)$. The effect of the factor Moment of Verbalization concerned the categories Orientation $\left(F(1,58)=8.68 ; P \leqslant 0.01^{*}\right)$ and Monitoring $(F(1,58)=26.42-$; $\left.P \leqslant 0.001^{* * *}\right)$.

To get more insight into which subprocesses were expressed more by the successful pupils or under the condition Marks two MANOVAs with the factors Instruction, Student Level and Moment of Verbalization were carried out, the first MANOVA with the subprocesses of the category Orientation as variates and the second MANOVA with the subprocesses of the category Monitoring as variates. Concerning the factor Student Level more orientation processes like 'Reflecting on foreknowledge' $\left(F(1,58)=12.98 ; P \leqslant 0.001^{* * *}\right)$ and 'Reflecting on gaps in the foreknowledge' $\left(F(1,58)=11.73 ; P \leqslant 0.001-^{* *}\right)$ were expressed. Means were respectively $2.9(S D=2.7)$ and $0.3(S D=0.6)$ for successful pupils and $1.6(S D=2.0)$ and $0.1(S D=0.1)$ for unsuccessful pupils. Although the factor Student Level had no main effect on the category Directing and Testing, for some univariate tests an effect turned up for the processes 'Process selection' $\left(F(1,58)=10.13 ; P \leqslant 0.01^{*}\right)$ and 'Making summaries' $\left(F(1,58)=10.74 ; P \leqslant 0.01^{*}\right)$. Means were respectively $14.9(S D=11.1)$ and $0.5(S D=0.8)$ for successful students and $8.1(S D=7.0)$ and $0.1(S D=0.3)$ for unsuccessful students. Concerning the factor Moment of Verbalization and the category Orientation there was an effect on the process 'Reflecting on foreknowledge' $\left(F(1,58)=8.95 ; P \leqslant 0.05^{*}\right)$, with a mean of $1.7(S D=1.7)$ for the condition No Marks and $2.9(S D=2.9)$ for the condition Marks. Concerning the category Monitoring the factor Moment of Verbalization had an effect on the processes 'Noting task characteristics' $\left(F(1,58)=29.18 ; P \leqslant 0.001^{* * *}\right)$, 'Noting one's own activities' $\left(F(1,58)=35.02 ; P \leqslant 0.001^{* * *}\right)$, 'Noting uncomprehended words' $(F(1,58)=10.47$; $\left.P \leqslant 0.01^{*}\right)$ and 'Noting uncomprehended text fragments' $\left(F(1,58)=11.28 ; P \leqslant 0.01^{*}\right)$. Means for these processes were $3.8(S D=3.5), 3.3(S D=2.6), 0.4(S D=0.7)$ and $0.8(S D=1.1)$ for the condition No Marks and $6.9(S D=5.5), 6.3(S D=4.4), 0.7(S D=0.8)$ and $1.4(S D=1.8)$ for the condition Marks, consecutively.

Because the variable Student Level is just an a-priori grouping of pupils it is not certain that the same differences in on-going processes during learning mark these two groups when a direct relation between processes and learning performance is made. This direct relation was made by regression analyses. By means of All Possible Subsets Regression the set of 50 subprocesses was reduced to a set of nine subprocesses still having a multiple $R^{2}$ of 0.61 (adjusted $\hat{R}^{2}$ of .53$)(F(10,53)=8.22 ; P \leqslant 0.001)$ concerning the test performances. This selection was accompanied by a reduction in the multiple $R^{2}$ of 0.22 . Selection of the variables was done on the basis of their contribution to $R^{2}$. After All Possible Subset Regression for each category, processes of each category were selected on basis of their contribution to the multiple $R^{2}$ to form a set of predictors. After running an All Possible Subset Regression once more a final selection of processes took place by eliminating those processes of the set with a contribution to $R^{2}$ of less than 0.01 . For selected processes and their contributions to $R^{2}$, see table 1 . 
Table 1

Categories and subprocesses and their contributions to $\mathrm{R}^{2}$ concerning learning performances on the test (test 1) and the retention test (test 2)

\begin{tabular}{|c|c|c|c|}
\hline \multirow{2}{*}{ Category } & \multirow[t]{2}{*}{ Subprocess } & \multicolumn{2}{|c|}{ Contribution to $R^{2}$} \\
\hline & & TEST 1 & TEST 2 \\
\hline$\underline{\text { Transforming }}$ & Drilling & & 0.05 \\
\hline Orientation & $\begin{array}{l}\text { Going through a subject list } \\
\text { Reflecting on gaps in the foreknowledge }\end{array}$ & $\begin{array}{l}0.06 \\
0.01\end{array}$ & 0.06 \\
\hline Monitoring & $\begin{array}{l}\text { Noting uncomprehended words } \\
\text { Noting uncomprehended text fragment } \\
\text { Noting remainder study time }\end{array}$ & 0.02 & $\begin{array}{l}0.03 \\
0.01\end{array}$ \\
\hline Directing & $\begin{array}{l}\text { Planning } \\
\text { Process selection } \\
\text { Problem identification } \\
\text { Reading on after noting an uncom- } \\
\text { prehended word in the expectation that } \\
\text { classification will follow } \\
\text { Anticipation on the test }\end{array}$ & $\begin{array}{l}0.01 \\
0.06 \\
0.03\end{array}$ & $\begin{array}{l}0.02 \\
0.06\end{array}$ \\
\hline Testing & $\begin{array}{l}\text { Paraphrasing not in consensus with the text } \\
\text { Drawing conclusions not in consensus } \\
\text { with the text } \\
\text { Comparing two or more textfragments } \\
\text { Recalling } \\
\text { Making summaries }\end{array}$ & $\begin{array}{l}0.09 \\
0.02 \\
0.02\end{array}$ & $\begin{array}{l}0.02 \\
0.03\end{array}$ \\
\hline
\end{tabular}

Tableau 1

Catégories, sous-processus et leur contribution au $\mathrm{R}^{2}$ relatif aux performances aux tests 1 et 2

For the prediction of the scores on the retention test paper performance other processes were relevant (see table 2). The selection of these processes resulted in a reduction of $R^{2}$ with 0.18 , so that the set of these processes had a multiple $R^{2}$ of 0.53 (adjusted $\hat{R}^{2}$ of $0.44)$ and a significant regression $(F(9,54)=6.42 ; P \leqslant 0.001)$.

A series of regression analyses was carried out to check what the selected subsets contributed more to $R^{2}$ than the more easily gathered information such as Student Level, Competence, Metamemory, Learning Concept and Reading Succession. The change of $R^{2}$ by entering a subset into the regression analyses was tested on its significance by the formula of Kerlinger and Pedhazur (1973; Simons, 1980). Adding the subset constantly caused a significant change in the prediction of the dependent variable performances on the test paper or retention test paper (see tables 2 and 3).

Table 2

Change in percentage of explained variance $\left(\mathrm{R}^{2}\right)$ of the test paper performances by adding the process set to the regression equation

\begin{tabular}{lcccccc}
\hline \multicolumn{5}{c}{ Dependent variable: test paper performances } & & \\
\hline Predictor & $R^{2}$ & $\begin{array}{c}R^{2} \text { (predictor } \\
\text { + process set) }\end{array}$ & $\Delta R^{2}$ & $F$ & $D F$ & $P<$ \\
\hline Student Level & 0.16 & 0.65 & 0.49 & 7.00 & 10,50 & 0.005 \\
Competence 1 & 0.02 & 0.61 & 0.59 & 7.56 & 10,50 & 0.005 \\
Competence 2 & 0.01 & 0.61 & 0.60 & 7.69 & 10,50 & 0.005 \\
Metamemory & 0.05 & 0.61 & 0.56 & 4.26 & 10,50 & 0.005 \\
Metacognition & 0.18 & 0.64 & 0.46 & 3.59 & 10,50 & 0.005 \\
Reading suc. & 0.04 & 0.62 & 0.58 & 7.63 & 10,50 & 0.005 \\
Learn. concept & 0.00 & 0.63 & 0.63 & 8.51 & 10,50 & 0.005 \\
\hline
\end{tabular}

Tableau 2

Changement dans le pourcentage de variance expliquée $\left(\mathrm{R}^{2}\right)$ des scores au test de performance, si l'on adjoint les variables processus à l'équation de régression 
Table 3

Change in percentage of explained variance $\left(\mathrm{R}^{2}\right)$ of the retention test paper performances by adding the process set to the regression equation

\begin{tabular}{lcccccc}
\hline \multicolumn{7}{c}{ Dependent variable: retention test paper performances } \\
\hline Predictor & $R^{2}$ & $\begin{array}{c}R^{2} \text { (predictor } \\
\text { + process set) }\end{array}$ & $\Delta R^{2}$ & $F$ & $D F$ & $P<$ \\
\hline Student Level & 0.25 & 0.56 & 0.31 & 3.99 & 9,51 & 0.005 \\
Competence 1 & 0.07 & 0.55 & 0.48 & 6.04 & 9,51 & 0.005 \\
Competence 2 & 0.01 & 0.53 & 0.52 & 6.27 & 9,51 & 0.005 \\
Metamemory & 0.17 & 0.55 & 0.38 & 3.91 & 9,51 & 0.005 \\
Metacognition & 0.56 & 0.69 & 0.13 & 1.07 & 9,51 & $\geqslant 0.25$ \\
Reading suc. & 0.01 & 0.55 & 0.54 & 6.80 & 9,51 & 0.005 \\
Learn. concept & 0.00 & 0.54 & 0.54 & 6.65 & 9,51 & 0.005 \\
\hline
\end{tabular}

Tableau 3

Changement dans le pourcentage de variance expliquée $\left(\mathrm{R}^{2}\right)$ des scores au test de rétention, obtenu si on adjoint les variables de processus à l'équation de régression

In the same manner it was tested how much the test questions predicted the exercise performances. Only in the case of this retention test did the questions account for 25 per cent of the explained variance. Even then the subset of variables explained more (see table 4).

Table 4

Percentage of explained variance of the exercises by means of the test questions and the process set

\begin{tabular}{lcccccc}
\hline \multicolumn{7}{c}{ Dependent variable: exercise performances } \\
\hline Predictor & $R^{2}$ & $\begin{array}{l}R^{2} \text { (predictor } \\
+ \text { process set) }\end{array}$ & $\Delta R^{2}$ & $F$ & $D F$ & $P<$ \\
\hline $\begin{array}{l}\text { Questions } \\
\text { Retention questions }\end{array}$ & 0.00 & 0.21 & 0.21 & 1.33 & 10,50 & $\geqslant 0.25$ \\
\hline
\end{tabular}

Tableau 4

Pourcentage de variance expliquée de la réussite aux exercices en fonction des questions du test et des variables de processus

\section{Discussion}

The results of the study reported here were: 1) Variation in the kind of instructions and examples used to introduce the thinking-aloud method did not result in different protocols. 2) The instruction to verbalize thoughts at certain marks resulted in more verbalizations, especially with regard to orientations and monitoring. 3) Successful pupils differed from the less successful ones in the number of orientations, especially with regard to the processes 'Reflecting on foreknowledge' and 'Reflecting on gaps in foreknowledge'. Successful pupils also showed more directing and testing activities, especially concerning the processes 'Process selection' and 'Making summaries'. 4) A selected set of process variables improved the prediction of learning performance by aptitudes and conceptions significantly. 5) There were significant differences between the best predictors of the immediate and the retention measures.

Although we found significant differences between the Marks-No Marks instructions in the total number of verbalizations and in orientations and monitoring in favour of the 
Marks instruction, we prefer a No Marks condition, for the following reasons: a) The difference in amount of verbalizations was not so large as one might have expected. b) Under the Marks condition rather trivial verbalizations, like «I am reading» and «I am still doing the same» dominated. c) Pupils reported that they were disturbed by the Marks, forcing them to verbalize thoughts at moments they had none. In prior publications based on the results with regard to informative texts and to vocabulary the same conclusions were reached as to the effects of Marks (De Jong, 1987a,b).

The instructions and examples given in introducing the thinking-aloud method did not have any effects on learning processes or learning performance. Thus, in explicitly directing the pupils to verbalize thoughts related to self-regulation and in giving only examples of self-regulatory cognitions, we did not increase the number and kinds of verbalizations. This means that in future we will give direct instructions. This result also agrees with conclusions reached in studies with informative texts and vocabulary.

Although the successful pupils make more reflective remarks with regard to their foreknowledge one has to take into account that seventeen of these pupils had a computer at home as compared to eleven of the less successful pupils. Therefore the successful pupils had more opportunities to reflect on their foreknowledge. Of more interest is the fact that the successful pupils change more often from the on-going activity to another and make more summaries than the less successful pupils. These results are in accordance with the earlier results of Simons and Lodewijks (1987) an the study of De Jong (1987a) about informative text learning.

In case one has to retrieve information from long-term memory other processes during learning are also relevant. Differences in retention test performances are better explained by processes such as 'Drilling' 'Recalling' and 'Making summaries' which are more directed towards remembering information in the long term.

One might ask oneself whether the better prediction of the learning performances by the set of selected processes is not just caused by a too simple operationalization of something like learning conception, competence, metamemory, or metacognition. This may be, but in comparison with another study of text processing the prediction of the variable Metacognition is much higher. Therefore feedback during the test is reflected in this variable, which shows that the operationalization of this variable is sensitive to the pupils' awareness of their actual test performance.

In addition to this, it can be said that even more sophisticated variables such as Student Level and Reading Succession do not have much better predictions of the learning performances. Even the performances on the text exercises are better predicted by the selected set of processes than by the questions which tested the subjects mainly on their comprehension of the text.

So it can be concluded that one gets the understanding of the different learning performances under control by inferring metacognitive processes out of on-line thinking-aloud protocols.

\section{References}

De Jong, F. P. C. M. (1987a). Differences in Self-Regulation Processes Between Successful and Less Successful Students and the Prediction of Learning Performances In Case Of Comprehension and Learning From Text. In P. R. J. Simons \& G. Beukhof (Eds.), Regulation in learning (pp. 33-46). Den Haag: SVO-Selecta-reeks

De Jong, F. P. C. M. (1987b). Registration of Self-Regulation Processes By Means Of Thinking Aloud During Text Processing. Paper presented at the ORD, May 25-26, in Groningen, The Netherlands.

Flavell, J. H., \& Wellman, H. M. (1977). Metamemory. In R. V. Kail, Jr. \& J. W. Hagen (Eds.), Perspectives on the development of memory and cognition (pp. 3-33). Hillsdale, New Jersey: Erlbaum.

Kerlinger, F. N., \& Pedhazur, E. J. (1973). Multiple regression in behavioral research. New York: Holt, Rinehart \& Winston.

Olshavsky, J. E. (1976). Reading as problem solving. Reading Research Quarterly, 12, 654-674. 
Simons, P. R. J. (1980). Vergelijkenderwijs: onderzoek naar de invloed van metaforen op het leren. Tilburg: Van Spaendonck. [Comparing: Research on the Influence of Metaphores on Learning].

Simons, P. R. J., \& Lodewijks, J. G. L. C. (1987). Regulatory cognitions during learning from texts. In E. de Corte, H. Lodewijks, R. Parmentier \& P. Span (Eds.). Learning and Instruction (pp. 357-368). Leuven: Pergamon.

Simons, P. R. J., \& Vermunt, J. D. H. M. (1986). Self-regulation in knowledge acquisition: a selection of Dutch research. In G. Beukhof \& P. R. J. Simons (Eds.), German and Dutch research on learning and instruction (pp. 101-135). Den Haag: SVO-Selecta-reeks.

Vermunt, J. D. H. M., Lodewijks, J. G. L. C., \& Simons, P. R. J. (1986). Hardop-denken als onderzoeksmethode naar regulatieprocessen bij tekstbestudering. Tijdschrift voor Onderwijsresearch, 11, 187-202. [Thinking-Aloud as a Research Method on Regulation Processes during Text Processing].

\section{Appendix 1}

The Computer - The Key-Board

$<$ E $>$ Numerical Keys (Key-pad)

\begin{tabular}{|c|c|c|c|}
\hline $\begin{array}{c}\text { NUM } \\
\text { LOCK }\end{array}$ & $\begin{array}{c}\text { SCR } \\
\text { LOCK }\end{array}$ & SYS & WC \\
\hline $\begin{array}{c}7 \\
\text { HOME }\end{array}$ & $\begin{array}{c}8 \\
\text { UP }\end{array}$ & $\begin{array}{c}9 \\
\text { PGUP }\end{array}$ & - \\
\hline $\begin{array}{c}4 \\
\text { LFT }\end{array}$ & 5 & $\begin{array}{c}6 \\
\text { RGT }\end{array}$ & + \\
\hline $\begin{array}{c}1 \\
\text { END }\end{array}$ & $\begin{array}{c}2 \\
\text { DWN }\end{array}$ & $\begin{array}{c}3 \\
\text { PGDN }\end{array}$ & \\
\hline \multicolumn{2}{|c|}{$\begin{array}{c}0 \\
\text { INS }\end{array}$} & $\begin{array}{c}\bullet \\
\text { DEL }\end{array}$ & \\
\hline
\end{tabular}

Figure 3: Numerical keys

Read: ENTER

The Computer - They Key-Board

$<\mathrm{F}>$ The memory

A computer has a memory, just like you. All information appearing on the screen, either text, numbers, programs or commands, does not automatically go into the memory of the system. Everything you write down on a piece of paper does not go into your memory either. The computer even does not know anything if the information that exists in the memory or on the screen has not been fed to the so-called «processor" or working memory. In the first case we speak of the external memory.
A. The key-board
B. The keys
C. Function keys
D. Alphanumerical
E. Numerical
F. The memory
G. The ENTER-key
H. The cursor
L. Number one
M. Number zero
N. Capitals
O. Caps Lock
P. Knacks
Q. Table 1
R. Table 1 cont'd
S. Table 2
T. Correct
U. Remove
V. Repetition 


\section{$<\mathrm{G}>$ The ENTER-key}

The system does not react to the information that is only on the screen or in the memory. Transformation of the information from the screen to the working memory takes place when you push the ENTER-key, <--1. At that moment the information temporalily goes to the working memory, is given through to the "processor" and will the system react to that information as well. Information that exists only in the working memory and has not been written into the (external) memory by means of a special command will disappear from the working memory when the current falters or when the computer is switched off.

\section{The Computer - The Key-Board}

\section{$<\mathrm{L}>$ The number one}

This in contrast with the use of key-boards of some typewriters. There one can use the lower case letter 1 or the upper case letter I instead of a 1 .
A. The key-board
B. The keys
C. Function keys
D. Alphanumerical
E. Numerical
F. The memory
G. The ENTER-key
H. The cursor
L. Number one
M. Number zero
N. Capitals
O. Caps Lock
P. Knacks
Q. Table 1
R. Table 1 cont'd
S. Table 2
T. Correct
U. Remove
V. Repetition

A. The key-board
B. The keys
C. Function keys
D. Alphanumerical
E. Numerical
F. The memory
G. The ENTER-key
H. The cursor
L. Number one
M. Number zero
N. Capitals
O. Caps Lock
P. Knacks
Q. Table 1
R. Table 1 cont'd
S. Table 2
T. Correct
U. Remove
V. Repetition

The Computer - The Key-Board

$<Q>$ Table 1
A number of keys from the numerical key board wi
functions that you can use to go through the text
cursor.
\begin{tabular}{|l|l|}
\hline & THE NUMERICAL PART \\
\hline KEY & DESCRIPTION \\
\hline UP & The cursor goes up \\
\hline DWN & The cursor goes down \\
\hline LFT & The cursor goes left \\
\hline RGT & The cursor goes right \\
\hline
\end{tabular}

To be continued on text screen...

\section{Read: ENTER}




\section{Appendix 2}

$<\mathrm{F}\rangle$ Looking at a file

By means of the file name you can indicate which file you want to call up from the computer's memory and make appear the contents of that file on the screen. This you do by giving the type-command. After this command the computer types the whole of the file on the screen. If you only want to have a quick look to see what it was that was in the file you give this command:

\section{TYPE file name}

Do not forget to close the command with CR or the $<-1$ key.

\section{The Computer - The Editor}

\section{$<\mathrm{K}>$ Function keys 1}

The so-called function keys have a number of knacks when using the editor. These keys can be recognized by the $\langle\mathrm{F}\rangle$ on the key followed by a number. See figure 1 . A number of these keys is described in Table 1.
A. The memory
B. The ENTER-key
C. The cursor
D. Files
E. The file-name
F. Looking at file
G. The editor
H. Call up a file
K. Function keys 1
L. Figure 1
M. Table 1
N. Table 1 cont'd
O. Function keys 2
P. The buffer
Q. Move
R. Function key F2
S. In a buffer
T. More lines
U. Out of a buffer

The Computer - The Editor

$<\mathrm{L}>$ The function keys

\begin{tabular}{|l|l|}
\hline F1 & F2 \\
\hline F3 & F4 \\
\hline F5 & F6 \\
\hline F7 & F8 \\
\hline F9 & F10 \\
\hline
\end{tabular}

Figure 1: Function keys
A. The memory
B. The ENTER-key
C. The cursor
D. Files
E. The file-name
F. Looking at file
G. The editor
H. Call up a file
K. Function keys 1
L. Figure 1
M. Table 1
N. Table 1 cont'd
O. Function keys 2
P. The buffer
Q. Move
R. Function key F2
S. In a buffer
T. More lines
U. Out of a buffer
A. The memory
B. The ENTER-key
C. The cursor
D. Files
E. The file-name
F. Looking at file
G. The editor
H. Call up a file
K. Function keys 1
L. Figure 1
M. Table 1
N. Table 1 cont'd
O. Function keys 2
P. The buffer
Q. Move
R. Function key F2
S. In a buffer
T. More lines
U. Out of a buffer 
The Computer - The Editor

$<\mathrm{M}>$ A survey

Table 1: Some function keys and the effects of using them

\begin{tabular}{|l|l|}
\hline \multicolumn{2}{|c|}{ FUNCTION KEYS } \\
\hline KEY & DESCRIPTION \\
\hline F4 & Cursor goes to the end of the line \\
\hline SHIFT F4 & Cursor goes to beginning of line \\
\hline F5 & Cursor goes to the end of the text \\
\hline
\end{tabular}

To be continued on the next screen...

\section{Read: ENTER}
A. The memory
B. The ENTER-key
C. The cursor
D. Files
E. The file-name
F. Looking at file
G. The editor
H. Call up a file
K. Function keys 1
L. Figure 1
M. Table 1
N. Table 1 cont'd
O. Function keys 2
P. The buffer
Q. Move
R. Function key F2
S. In a buffer
T. More lines
U. Out of a buffer

\section{The Computer - The Editor}

$<$ P $>$ The buffer

The buffer is a kind of storage room in the working memory of a computer in which you can put down a selected part of a file. You are parking, as it were, the selected part until you need it again. Such a selected part can, for example, be a piece of text.

\section{Read: ENTER}
A. The memory
B. The ENTER-key
C. The cursor
D. Files
E. The file-name
F. Looking at file
G. The editor
H. Call up a file
K. Function keys 1
L. Figure 1
M. Table 1
N. Table 1 cont'd
O. Function keys 2
P. The buffer
Q. Move
R. Function key F2
S. In a buffer
T. More lines
U. Out of a buffer

\section{Auto-régulation dans l'apprentissage a l'aide de textes}

Une expérience ayant pour but d'étudier l'influence des consignes d'apprentissage sur les processus d'auto-régulation durant la lecture, l'apprentissage et le contenu des protocoles de pensée à voix haute de 64 collégiens répartis en deux groupes en fonction de leur réussite scolaire a été réalisée. Les textes utilisés étaient de type procédural et présentaient les consignes d'utilisation d'un clavier relié à un ordinateur et d'un logiciel de traitement de texte. Les résultats indiqent que la variation des consignes d'apprentissage n'exerce pas d'influence sur l'appren- 
tissage et sur les protocoles de pensée à voix haute, tant quantitativement que qualitativement. Les principales différences entre les deux groupes s'observent pour les processus d'orientation, en particulier pour la réflexion sur leur pré-savoir et les lacunes de leur pré-savoir. Des différences se manifestent également pour les processus de sélection et de construction de résumés. Ces résultats sont confrontés à ceux qui ont été précédemment obtenus avec des textes explicatifs traitant de la biologie et interprétés à la lumière du modèle proposé par Simons et Lodewijks (1987).

Key words: Self-regulation, Metacognitive processes, Text learning, Thinking aloud.

Revision received: April 1988

Frank de Jong, Robert-Jan Simons. Tilburg University, P.O. Box 90153, 5000 LE Tilburg, The Netherlands.

Current theme of research:

Self-regulation of learning.

Most relevant publications in the field of Educational Psychology:

De Jong, F. P. C. M. (1987). Registration of Self-Regulation Processes with First Year Students of a HAVO-VWO Comprehensive School by Means of Thinking Aloud. In Christine Schwarzer (Ed.), Trends in European Educational Research (pp. 194-202). Braunschweig: Braunschweiger studien zur Erziehungs- und Sozialarbeitswissenschaft, 20.

De Jong, F. P. C. M. (1987). Differences in Self-Regulation Processes Between Successful and Less Successful Students and the Prediction of Learning Performances In Case Of Comprehension and Learning From Text. In P.R.J. Simons \& G. Beukhof (Eds.), Regulation in learning (pp. 33-46). Den Haag: SVO-Selecta-reeks.

Simons, P.R.J., \& Lodewijks, J.G.L.C. (1987). Regulatory cognitions during learning from texts. In E. de Corte, H. Lodewijks, R. Parmentier \& P. Span (Eds.). Learning and instrtuction (pp. 357-368). Leuven: Pergamon.

Simons, P.R.J., \& Vermunt, J.D.H.M. (1986). Self-regulation in knowledge acquisition: a selection of Dutch research. In G. Beukhof \& P.R.J. Simons (Eds.), German and Dutch research on learning and instruction (pp. 101-135). Den Haag: SVO-Selecta-reeks. 